\title{
Sharing economy: becoming an Uber driver in a developing country
}

Uber driver in a developing country

\author{
Eduardo Valente
}

Business Administration,

Pontificia Universidade Catolica de Minas Gerais, Belo Horizonte, Brazil

Roberto Patrus

Management Department,

Pontificia Universidade Catolica de Minas Gerais, Belo Horizonte, Brazil, and

Rosana Córdova Guimarães

Escola de Administração,

Universidade Federal do Rio Grande do Sul, Porto Alegre, Brazil

\begin{abstract}
Purpose - The purpose of this paper is to analyze why people have become suppliers in the sharing economy (SE) as Uber drivers in a developing country.

Design/methodology/approach - From a background on SE, car sharing and gig economy, the authors carried out a qualitative research. The analysis was based on 20 semi-structured interviews conducted with Uber drivers, and on the authors' participant observation as Uber drivers and passengers in the third largest Brazilian city, Belo Horizonte.

Findings - Empirical evidence shows that becoming an Uber driver is more a matter of solving unemployment on a more permanent way rather than a search for a temporary and flexible work to supplement income. Although there are benefits related to flexibility, income and social interactions, negative externalities identified herein lead to the conclusion that the overall work relations and conditions are negative.

Originality/value - Much in the literature of the SE is focused on understanding consumer behavior; this research, on the contrary, is focused on understanding producers, which indicates an incipient perspective. The contributions of this paper show that the SE merges into different distributive decentralized means of production that are seeing as profit/income generated from shareable assets.
\end{abstract}

Keywords Sharing economy, Uber, Car sharing, Gig economy

Paper type Research paper

\section{Introduction}

Sharing economy (SE) can be defined as a sharing socio-economic system, which includes the production and consumption of goods and services. Much in the literature of SE has focused on understanding consumers, which is known as collaborative consumption (Botsman \& Rogers, 2011; Cheng, 2016; Silveira, Petrini, \& dos Santos, 2016); and the producer's perspective has not yet been described in the discussion of what SE really means. The main study about production in SE focuses on understanding people's motivation toward sharing, such study comprehends distributive decentralized means of production of shareable assets (Benkler, 2004). Furthermore, it is possible to understand how intangible open source internet production has occurred with the paradigmatic cases of Wikipedia and Linux (Lessig, 2008).

(C) Eduardo Valente, Roberto Patrus and Rosana Córdova Guimarães. Published in Revista de Gestão. Published by Emerald Publishing Limited. This article is published under the Creative Commons Attribution (CC BY 4.0) licence. Anyone may reproduce, distribute, translate and create derivative works of this article (for both commercial and non-commercial purposes), subject to full attribution to the original publication and authors. The full terms of this licence may be seen at http://creative commons.org/licences/by/4.0/legalcode

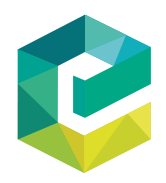

Revised 15 February 2019 Accepted 20 February 2019

Received 20 August 2018 
REGE

26,2

144

Important research in the field of SE has put effort into an anthropological approach toward differentiating sharing from gift and commodity exchange (Belk, 2007, 2010, 2014). This has recently led to an academic discussion on mutuality as a distinctive characteristic of sharing (Arnould \& Rose, 2016; Belk, 2016). There is in the academia a paradoxical perspective regarding this theme, since some scholars believe that SE is not sharing at all (Bardhi \& Eckhardt, 2012). Such paradox brings back the conceptual discussion that aims to differentiate SE considering its different perspectives - which go beyond consumption - leading to the necessary advancements in the theoretical foundations of this research area, which is still under development (Silveira, Petrini, \& dos Santos, 2016).

Therefore, the concept of sharing - in the new business era of decentralized internet production and intangible assets - may be understood as a form of micro capitalism (Petrie, 2016). Sharing is the foundation of a market where the surplus production capacity of personal goods can be used in different businesses in which individuals look for income generation - some scholars call this phenomenon sharing market (Valente \& Patrus, 2019).

Other relevant research areas of SE focus on the car transportation business related to sustainable mobility, specifically car sharing. Much has been discussed since the early 1990s with the emergence of automobile co-ownership, collective or public short-term car rentals rather than individual property, also considering ridesharing among coworkers, neighbors and family members (Steininger, 1994; Huwer, 2004). Nowadays, since the early 2000 s, car sharing has been impacted majorly due to new internet technologies that enabled the entrance of individuals that do not take into consideration the responsible consumption necessary to collaborate with the urban mobility or reduce car ownership costs. Rather than sharing a car, ridesharing includes common origins, destinations and routes; differently, Uber is a ride sourcing service (Shaheen et al., 2016).

The term "gig economy" has been used by studies focused on the SE workers, although they are often applied to describe the same business phenomena that include companies such as Uber (Malin \& Chandler, 2016). This interpretation points to research interests toward the providers, workers, suppliers and entrepreneurs of the SE. Therefore, the SE suits as a background for an empirical approach in aspects related to the individuals that are registered and serving others through these platforms. Only recently, the discussion of gig workers has been carried out (Graham, Hjorth, \& Lehdonvirta, 2017). Not much is known about the dynamics of the gig work in relation to the workers, their moves in and out and uses amid the different forms of employment (Donovan, Bradley, \& Shimabukuru, 2016).

Our study is a result of a master's dissertation and it seeks to answer the following research question:

$R Q 1$. Why do individuals become Uber drivers and how is it to work as one?

The objective is to analyze why people have become providers in the SE and how it feels like to be a provider in the SE. Based on Cheng (2016), there is a theoretical gap that this study aims to fill, i.e., the providers' perspective on the SE, rather than their relationship with collaborative consumption. Also, based on this author, another existing theoretical gap is that little about SE has been studied in developing countries, which prompts practical implications to business practices and the impact of technology, city managers and policy makers on issues about SE workers, work relations, conditions and even unemployment.

In this first part of the paper, we argue that there is an important theoretical and practical gap related to the reasons that lead people to become SE workers and how it is to work in an SE; even though sharing, in this context, is not sharing at all (Eckhardt \& Bardhi, 2015). In the second part, an SE concept is developed to further point out the differences that make sharing a unique type of economic distribution and it is now taken as a market for decentralized revenue production rather than a social production. In this conceptual background review, gig economy appears as synonym of SE with studies focused on SE labor. In the fourth part, 
we present information related to the methodological procedures of this qualitative research, which comprehends interviews conducted with Uber drivers and participant observation, as both driver and passenger, in the city of Belo Horizonte, Brazil. In the fifth part, we present the categories resulted from a content analysis in which the data collected is described. In the sixth and final part, we present the conclusion of the research and present some suggestions for future studies.

\section{Sharing economy, car sharing and gig economy}

Sharing is a term hypothesized by anthropologists to be a distinct distribution mode in comparison to gifting, which is the main theoretical background in the field and is defined by the reciprocity that maintains individual relationships with one another (Bird-David, 1990). This idea is included in recent studies that further reinforces that the absence of reciprocity in sharing is one of the main variables that distinguishes it from the gift and also commodity exchanges, in which the last defines reciprocity by the payment for a good or service (Benkler, 2004; Belk, 2007).

Defined by the collaboratively internet-based projects, Wikipedia and Linux, freely consuming and providing, are closely related to what sharing means among people with close relationships (Lessig, 2008). When it comes to tangible, physical and personal goods, a new set of more instrumental processes is more common, such as in car sharing. Cars are shareable goods, their extra seats and idle time provide an excess capacity that can be understood as a resource, which is better allocated when shared (Benkler, 2004).

Specific car sharing literature adds a pro-environmental behavior, which can be seen in some characteristics of this sort of sharing, such as responsible mobility, modal rationality, alternative to car ownership and lower costs (Huwer, 2004). Similar variables were found to be of secondary influence for users of Uber and Lift (Shaheen et al., 2016). It is important to point out that car sharing literature has focused on niches and communities that have common culture and goals; differently, the number of Uber users has grown from about 0 to 460,000 by the end of 2015 in the USA (Hall \& Krueger, 2016).

In recent years, many businesses have emerged under the sharing and collaboration banner. Different terms have also been presented and it has made more difficult to define where the original social production of the sharing ends and the market begins (Belk, 2014). Additionally, empirical evidence show that, in different SE enterprises, when the sharing mission is strongly adherent, trading activities are not robust, as well as when the trading volume is high, the sharing culture moves away (Schor et al., 2016). Therefore, according to some scholars, the presence of money, beyond cost division, jeopardizes collaboration; this way, sharing processes can turn into something much more instrumental, a commodity (Belk, 2014; Benkler, 2004; Lessig, 2008). Sharing parties become buyers and sellers in transactions with unknown individuals intermediated by digital platforms (Martin et al., 2015). As defined by Petrie (2016): "it's that an individual has a personal resource - either a service or tangible capital - that can be leveraged with a typically internet-enabled intermediary platform."

From this perspective, the mix between sharing as a social production and the market has become rather a part of a business phenomenon in which the collaborative cultural aspects are undermined by pricing and profit principles that can be found in digital platforms - currently, some billion dollars' worth intermediate (Bardhi \& Eckhardt, 2012). Furthermore, empirical evidence show that different SE sites have more or less market ability, and some dominant practices in a macroeconomic market institution may also be transported by people into sharing sites, such as inequality, hierarchy and power (Schor et al., 2016). Authors such as Botsman and Rogers (2011), Gansky (2012) and Lamberton and Rose (2012) define SE based simply on the possibility of temporary access to goods in comparison to traditional property ownership, a rhetoric that embraces a

Uber driver in a developing country 
REGE

26,2 society shift from property to access; that is, in this context, Uber users would no longer need to have cars of their own anymore (Schor \& Attwood-Charles, 2017).

This second view, which accepts the mix among the different types of economic distribution, is more applicable to what Rifkin (2001) called as "the age of access." The work criticizes the role of the internet in the changing structure of capitalism from a property/ materialistic society moving toward society network that is even more restrictive than the one before. He reviewed the work of Polanyi (1944/2013) to discuss about the commoditization of the cultural and social aspects of society. In a different perspective developed by Polanyi's studies, Granovetter $(1985,2005)$ argued that networks carry both cultural and social relationships in their economic transactions; commerce and social aspects are embedded in one another.

The decentralization process enabled the internet to own a sharing characteristic; however, the main aspects of the production process of personal properties may be better characterized by a market perspective. This can be called sharing market, i.e., people's personal goods and labor idle capacities can be sold in small portions to others through decentralized processes that result in revenue. In other words, individuals willing to become providers in this sort of business are looking at these sharing markets, at their own resources and of others and making decisions in search of opportunities to make money (Valente \& Patrus, 2019; Valente, 2017).

Beyond the previous idea that the provider's role in the SE is strictly related to the idle capacity of his/her properties and availability, the gig economy, according to the literature, encompasses aspects related to the individuals that are registered and serving others in these platforms. Some of these aspects are: the influence of flexibility and non-obligation to work with the eventual occurrence of risks (Malin \& Chandler, 2016); entrepreneurship and alternative revenue sources these individuals could be having (Burtch, Carnahan, \& Greenwood, 2018); individual profile and his/her employability in the gig economy/SE (Carr et al., 2017); the future of work, from jobs to gigs, differences between high, middle and low income classes (Foresight Alliance, 2016); Uber's driver-partner labor market (Hall \& Krueger, 2016) and so on.

In conclusion of this section, Leighton (2016) analyzed the regulatory framework related to Uber drivers concluding that it faces the same controversies and uncertainties of independent self-employed professionals. The author also considers that the changes from the traditional work relation to the flexible independent gig work are as radical as they were seen in the eighteenth century during the industrial revolution. This study points out the relevance of SE and its gig form of work and benefits. There has been either a cynical perspective or a romantic view surrounding this theme: the first one criticizes SE based on its traditional business methods with shareholders and profit motives; in other words, SE is not related to charity. The second one sees this relation as beneficial, although high levels of satisfaction is only found among people who are driving Uber as a second job, i.e., Uber as simply car sharing, which brings benefits to both car owners and passengers.

\section{Research method}

This research presents a qualitative case study with descriptive characteristics and was conducted in order to enable the analysis of various sources of primary and secondary empirical data (Yin, 2010) regarding the productive process of Uber.

We conduced 20 interviews with Uber drivers in the city of Belo Horizonte, Brazil. In order to have access to them, the first author of this paper signed himself in as a passenger and switched from all other transportation modes to use solely Uber during the data collection period, which lasted about one month and took place in a centralized and busy region of the city. Drivers were selected through the app's ride request and approached during the ride. This also enabled the participant observation and secondary 
data found on the passenger's app and official website, with information available in text and in video formats.

In order to achieve a necessary descriptive standardization of the data, drivers were interviewed with a semi-structured protocol with questions elaborated based on the literature reviewed herein, as presented in the previous sections (Yin, 2010). Questions focused on the driver's background, their decision process to become an Uber driver, their operation processes as drivers, how they use the service and for what reasons. The interviews were recorded and transcribed.

In order to access more information on the drivers, the first author signed himself in as a driver. The application process and the information related to the driver-passenger relationship through the app was collected using participant observation and the data were standardized using the semi-structured protocol. Although participant observation was planned to be used to collect data from the admittance process and from the specific Uber Driver App, Uber had requested that the author took rides or they would suspend the driver's registration. The first author took rides and wrote down a few notes also using the semi-structured protocol.

The drivers/informants demographic information, presented in Table I, was collected based on other studies (Bardhi \& Eckhardt, 2012). The goal of this data collection was to characterize the Uber drivers within the group interviewed; we found substantial correlations in the data in regards to profession, car property and income, which will be described throughout the analysis section. We did not find any systematic differences between marital status and age and, also, no women were interviewed in our study, although we recognize the existence of women drivers in the city. This table was also important because it had not yet been accomplished in the literature consulted by us and may be considered for validity purposes in future studies.

The interviewees are anonymous and are referred to by the number on the table. About the information presented, the income is shown in US\$ converted from BRL; the exchange rate was calculated on August 8, 2018 (US $\$ 1.00=$ BRL3.75). Some interviewees
Uber driver in a developing country

\begin{tabular}{rrlllr}
\hline No. & Age & Profession & Car property & Marital status & Income (US\$) \\
\hline 1 & 35 & Electrical technician & Owner & Married & $1,600.00$ \\
2 & 34 & Cook & Owner & Single & $1,333.33$ \\
3 & 43 & Car salesman & Co-owned & Married & 800.00 \\
4 & 28 & Taxi driver & Owner & Married & 800.00 \\
5 & 48 & Private driver & Rents from a friend & Married & 400.00 \\
6 & 40 & Computer Technician & Rents from a non-relative & Married & 266.67 \\
7 & 36 & Watchman & Rents from car rental agency & Single & 266.67 \\
8 & 31 & Private driver & Owner & Married & 533.33 \\
9 & 56 & Real estate broker & Owner & Married & $1,333.33$ \\
10 & 31 & Manager & Owner & Married & 800.00 \\
11 & 35 & Engineer & Borrows from a relative & Married & $1,333.33$ \\
12 & 36 & Private driver & Owner & Married & $1,066.67$ \\
13 & 45 & Manager & Owner & Married & $1,066.67$ \\
14 & 47 & Taxi driver & Owner & Married & 533.33 \\
15 & 44 & Accountant & Owner & Married & $1,066.67$ \\
16 & 53 & Taxi driver & Borrows from a relative & Married & 533.33 \\
17 & 40 & Manager & Owner & Single & $1,866.67$ \\
18 & 43 & Retiree & Rents from a non-relative & Married & 400.00 \\
19 & 42 & Manager & Owner & Married & 800.00 \\
20 & 44 & Teacher & Owner & Single & $1,333.33$
\end{tabular}

Table I. Interviewees' demographic variables 
REGE

26,2

responded their monthly income to be around US\$266.67, which is close to the Brazilian minimum wage.

The data analysis was conducted through content analysis according to Gil (2002) and Moraes (1999). The content analysis followed these steps, according to Moraes (1999): fragmentation of texts and codification of each unit; rewrite each unit so that it assumes a complete possible; and the attribution of a name or title to each unit produced. Further steps were used to merge, divide or exclude units in cycles of rereading and reinterpreting

fragments under each unit. The content analysis of the interviews resulted in Table II, which presents the codes, subcategories and categories of the research. This process was done using free software QDA Miner. The software's tools were used to code fragments, group codes in categories and subcategories, build reports on coding proximity, correlations, overrides, frequency and building spreadsheets, all of which also supported the interpretation of the data and the circling process of revising codification.

In sum, participant observation as a driver and as a passenger, secondary data from the app's different interfaces, official website (videos and texts) and 20 interviews conducted with Uber drivers were triangulated through the next sections. The research presented 572 interview segments grouped into 26 codes, which were grouped into 8 subcategories that were again grouped into 3 categories. We also had 33 pages of interview transcripts; 70 pages of secondary data framed into the interview protocol, of which 38 pages were Uber's contracts with drivers; plus 46 min of videoshoots.

\section{Data analysis and discussion}

This section aims to present the analysis of the data and was structured in three parts, one for each category, each part with a subsection based on the subcategories, as presented on Table III, "research categories and subcategories and codes." The purpose of this table is to report the categories, to introduce the discussions and to provide a broader view of the results described herein.

\subsection{Uber cars: between access and property}

One of the categories identified in the data analysis was simply called as "the car." It was classified in order to encompass two subcategories, the "property of the car" and the "characteristics of the car." On Table II, in the first column, the category "Car" is described, along with the subcategories and the codes of each subcategory, and the second column presents the number of segments grouped in each of these layers.

Most of the interviewees were already owners of the cars they were using to drive with Uber. These segments were coded as "uses the car he already had." They presented how the availability of the already owned car and the individual's own availability were substantial to spawn the idea of becoming a driver. After the opportunity had been identified, the vehicle owned was evaluated according to specific characteristics that would classify it as appropriate or not - these characteristics were (primarily but not hierarchically): their own comfort as

\begin{tabular}{lr}
\hline Car & 55 \\
\hline Car property & 23 \\
Uses the car he already had & 16 \\
Rents the car & 5 \\
Borrows the car & 2 \\
Car characteristics & 32 \\
Maintenance and costs & 27 \\
Car models & 5 \\
Source: Research data &
\end{tabular}




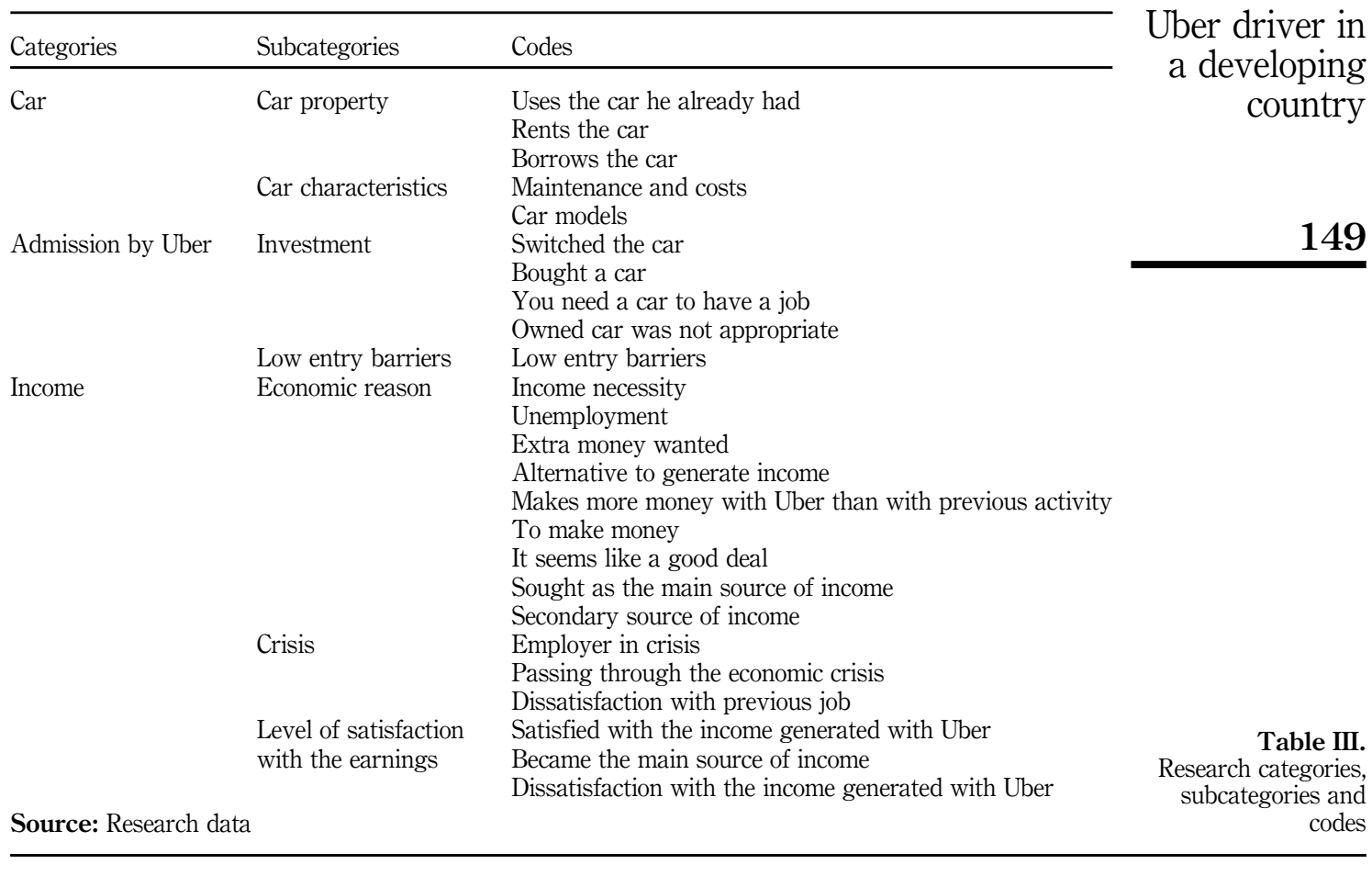

drivers, passenger's perception of comfort and vehicle reliability. Second, after the drivers had initiated the activities, they became aware of the operational costs, drawing to the conclusion that these costs were higher than the drivers had initially expected. The main costs were related to car ownership and usage, insurance, maintenance, fuel and depreciation:

My car is the car I already had. I thought it was ideal because it's very comfortable, but later I learned I was going to need something with fewer costs to maintain, it was so much more than I expected. I am going to have to exchange it for something more fuel efficient and lower maintenance costs. (Respondent 10)

An interesting insight provided by a former taxi driver, now Uber driver, was that switching to Uber was a decision also driven by the possibility to also have his personal property need fulfilled along with the professional goals. Rayle et al. (2016) affirmed that the resource allocation of vehicles is improved in Uber, considering that the automobile is used by the driver personally and professionally, instead of a taxi used only for work.

A second car property analyzed was the rental, which also had two distinct origins: first, enabled by one of Uber's partners, which was seen as a positive tool due to the readiness to start operating, switch vehicles with mechanical problems or return them with no extra costs for the driver; second, drivers have found there were private car owners willing to make business with Uber drivers; in other words, cars were accessed in an informal renting system provided by previously unknown individuals.

The first situation occurs in regular rental ways with discounts given for Uber drivers. But the second renting way - between Uber drivers and informal car rentals - was considered to be unique. Two interviewees described their experience renting from nonrelatives, and one interviewee described a similar experience when renting a car from a friend. In order to demonstrate these situations, we will transcribe a part of the interview 
REGE

26,2

conducted with Respondent 7 . He owned a car, considered too old to be used as an Uber vehicle, and eventually met an individual he had never met before willing to rent him a suitable vehicle:

I met this guy in a Whatsapp group of drivers. As far as I know, it's my renter's only vehicle, but it seems to be a good business because he told me he was willing to buy another car to do the same thing. I pay him $\$ 390.00$ a month and the car is worth about forty thousand, so I think it is good business. It is also good business for me because I don't have the means to exchange my old car. Just like me, there are many people interested in becoming a driver and will need to rent a car this way. (Respondent 7)

Respondent 7's statement is related to the lack of barriers mitigated by the SE, in which the need to own a certain resource is a basic condition to become a service provider. In this case, having access to a car is a prerequisite to access the Uber driver gig and, through sharing, the access of the provider's to the service was enabled through the network of decentralized economic transactions. Despite the networks of drivers focused on cooperation and socialization, the access to the production resource adds commodity value to the collaboration construct, which results in a sharing market. It results in people willing to assume higher risks than they would normally do around the promise of better, although informal, income.

In the third type of car property identified, we analyzed how Uber drivers borrow cars from their relatives or friends - such form of sharing appears in the literature as a distinct type of distribution (Belk, 2007, 2010). When the car had been borrowed from or bought with relatives or friends, it became a mutual resource, in which participants took turns for personal or professional - in this case, Uber - use. Remarkably and well related to literature, no money is involved. In the first statement we got regarding this issue, the father had lent his already owned car to his son (interviewee), so he could become an Uber driver:

My wife and I became unemployed and we have a 3 month old daughter. The idea to drive with Uber came from my father, as he offered to lend me his car. (Respondent 11)

In the second case, a daughter lent the car to her father, a former taxi driver. The driver recognizes that this specific car is not the most appropriate for this sort of business:

It's my daughter's car and it's the only car in the family. We take care of and use it as if it was ours (mine and my wife's) too. She already had it and I knew it was not the most appropriate car for this use. I will need to install a natural gas equipment for the car to become more fuel efficient. (Respondent 16)

Sharing was identified within friends and/or relatives; but no sharing elements were found in Uber. It was also noted that in this sort of sharing process, the absence of payment for the use of the vehicle made clear that the feeling of ownership was stronger in a sense of mutuality rather than reciprocity. According to Respondent 11: "the car is not mine, it's my dad's, but I don't pay for it neither he wants me to"; and Respondent 16: "my wife and I helped her (the daughter) to buy this car and we all use it and take care of it, she is the one who came up with the idea to use it here (as an Uber car)".

Cars used for Uber do not need to be bought. In this sense, cars do seem to exemplify the property update concept into an access-based concept, which is for some authors the symbol of the update (Abramovay, 2012). It is also clear that, beyond sharing a car with friends and relative, the idle capacities of production can now be acquired or sold (Cannon \& Chung, 2014), which creates two sharing markets: one within Uber, and the other one related to the informal market boosted by the drivers' network.

In the second subcategory "characteristics of the car," the main code in segment was "maintenance and costs." A car needs to be in good conditions to be driven long hours, 
while generating an income significantly higher than the costs with maintenance and other expenditures. Still, the main characteristic of the car was analyzed as "it was available" - viewed previously in this section - considered more important than the vehicle model and specification, which could increase the expenditures with maintenance and other costs.

This idea becomes more complete as drivers relate that they decided to use the car already available but later realized that the model was not appropriate: the vehicle needed to be more fuel efficient; the maintenance should be less expensive or not very frequent; the comfort for the driver and passengers should be better; and larger trunks, which comes along with larger and more expensive car models. Considering the driver's ability to generate more income, some of them responded that the cars needed to consume less fuel, which could be possible by switching to a different model.

Along with fuel efficiency, alternative energy sources were pointed out as a way to reduce costs, without mentioning its benefits to the environment. Many studies in the literature focus on the sustainability aspect of the SE, especially and historically regarding car sharing (Cohen \& Kietzmann, 2014) - although the sustainability variables are of lower interests to ridesharing users (Rayle et al., 2014) and to Uber drivers, according to our data analysis:

It's the car I already had. I think it's important to tell you that I want to acquire a hybrid model so I can reduce my fuel costs, which are now up to $35 \%$ of my gross profit. (Respondent 12 )

For some interviewees, if the car is larger and more comfortable, it is acceptable to spend more with fuel. It reduces the dissatisfaction with the lower margin because the driver feels that he is paying for the extra comfort:

It's a great car, comfortable, spacious, it's terrible in fuel consumption, but it's worth it. (Respondent 7)

At last, depreciation was one of the costs analyzed. Former taxi drivers interviewed herein evaluated that the difference between Uber's lower fares and the Taxis could be justified by the lack of including the depreciation of the vehicle (on Uber's side); when the depreciation is taken into consideration, taxi fares tend to be higher:

Taxi fares are higher because the drivers include the depreciation of the vehicle in the price and they have learned about it a long time ago, which is the biggest mistake that many of these new drivers make. (Respondent 14)

In triangulation with the secondary data collected, regarding Uber's negligence in including the cost of depreciation, we analyzed that the pricing of the fare is not based on the driver's operational costs. Depreciation is a component of the operational costs, although Uber's fare varies and adapts to the market's supply and demand predictions, which attracts passengers and drivers. In the following section, we will address the facts that Uber is "easy to enroll in and easy to quit"; there is a widespread availability of cars; the register of new drivers is unrestricted, all of which enables the establishment of Uber's pricing mode. Risks and uncertainty along with unknown high costs and other factors are incentives that make drivers quit Uber.

\subsection{Uber drivers admission and permanence barriers}

The category "Admission by Uber" relates to the motives and means necessary for a person to sign up as a driver by Uber. On Table IV, in the first column, the category "Admission by Uber" is described, along with the subcategories and the codes in each subcategory, and the second column presents the number of segments grouped in each of these layers.

Considering the drivers' admittance, besides the will/need to make more money, the car and the driver were already available. Although interviewees reported they had made an
Uber driver in a developing country 
REGE

26,2

152

investment in order to join Uber - they either bought/switched their car, or even rented/ borrowed a vehicle - drivers perceive a high risk in such investments. Also, the uncertainty related to the profitability indicates a higher risk when the driver considers buying or renting a car. This was coded as "you need to have a car to have work" and it signals that the right way of joining Uber is by already owning a car, which indicates a barrier for admitting new drivers:

My brother rents a car, makes less money than I do, working a lot more hours. (Respondent 12)

This relates to what Cannon and Chung (2014) proposed that the high value of the production good/asset creates an entering barrier, although for the individuals who already had the vehicle the admission process is simpler. Uber tries to reduce such barrier by promoting discounts with partner car rentals and dealerships.

Some of the drivers interviewed reported having switched his car in order to adapt to Uber. Respondent 1 said he started out with a compact car, but came to the conclusion that something more spacious would be better for the passengers. Yet, he decided, opposing to the previous report, that fuel consumption was his highest cost and went for a downgrade by purchasing a compact car. Uber also imposes a maximum vehicle age, so Respondent 14 had to get a newer car to be accepted as a driver. In a different case, two friends formed a society and bought a car specifically to work with Uber. Baumeister and Wangenheim (2014) also noted that some investment is needed to adapt to the rules; in the Uber case, a four-door car and is mandatory, and the vehicle year must be 2008 or newer. Such requirements benefit the individuals that already have the appropriate vehicle; these individuals are the ones with easier access to this form of decentralized economy in a productive and profitable way.

As presented before, the property origin varies. Some of the property types facilitate and reduce entrance barriers, but they indicate higher risks, therefore raising permanent barriers: by renting out from another person; by borrowing one from a relative; through Uber partner car rentals and dealerships.

In the participant observation, when registering as a driver, the insurance was not requested by the company in none of the steps of the admittance process. The contract "General Terms and Conditions of Digital Intermediated Services[1]" establishes that the driver is the only one responsible for the vehicle maintenance, insurance and the legal licenses to operate and render Transportation Services. In the USA, specific legislation was approved in order to demand mandatory insurance to work with Uber and Lyft (Cannon \& Chung, 2014). It is important to point out that taxes and legalization of the activities were also solely attributed to the drivers. This seems to be a way to manage drivers as nonemployees (Malin \& Chandler, 2016), and to avoid problems in the future (Cannon \& Summers, 2014). Contractually, the drivers hired Uber to access the right to utilize Uber's tools in the driver's application.

Table IV.

Category: admission by Uber

\begin{tabular}{lr}
\hline Admission by Uber & 14 \\
\hline Investment & 10 \\
Switched the car & 5 \\
Bought a car & 2 \\
You need a car to have a job & 2 \\
Owned car was not appropriate & 1 \\
Low entry barriers & 4 \\
Low entry barriers & 4 \\
Source: Research data &
\end{tabular}


In case new regulations come up, newer and larger barriers could emerge, which would raise transaction costs and restrict Uber's growth in terms of number of drivers by turning admission into a more exclusive process. Although Uber has been operating the city since 2014, specific regulation for it has not yet been released.

\subsection{To whom is the income generated with Uber?}

The category "income" was sub categorized to group codes that compose the "economic reasons," explained mainly by the need to generate income and unemployment; level of satisfaction with the income; the driver's decisions when highly satisfied and motives for low satisfaction; reasons why Uber is a temporary solution during the crisis; and, at last, the costs of operation reported by the drivers (related to dissatisfaction with the income generated from the activity). On Table V, in the first column, the category "Income" is described, along with the subcategories and the codes of each subcategory, and the second column presents the number of segments grouped in each of these layers.

4.3.1 The economic reasons to become an Uber driver in times of crisis. Unemployment was one of the strongest arguments for the need for more income. For this reason, "economic reason" was analyzed along with "crisis." Interviewees detailed the unemployment process in similar narratives. In general, the employer had been affected by the recession (coded as employer in crisis), there were overloaded job positions, and, ultimately, the employee ended up resigning or being dismissed:

The company I worked for was in crisis and they began cutting hours and other expenses.

The work environment was unbearable, exhausting. I'm still there but I got prepared for the worse,

so I switched my car and signed up as an Uber driver. (Respondent 17)

In this case, the availability of the appropriate vehicle and work force (due to unemployment) led to the work opportunity with Uber. It is important to point out that this respondent was in search of any means of income for a temporary period of time, in which he could be self-employed, due to the economic recession:

The crisis has been ruthless. When it ends, I hope my business will go back to normal, I don't want to be here anymore, I want to go back to my profession. I wish I did not need Uber ever again. (Respondent 6)

\begin{tabular}{lr} 
Income & 86 \\
\hline Economic reason & 49 \\
Income necessity & 12 \\
Unemployment & 12 \\
Extra money wanted & 7 \\
Alternative to generate income & 5 \\
Makes more money with Uber than with previous activity & 4 \\
To make money & 3 \\
It seems like a good deal & 2 \\
Sought as the main source of income & 2 \\
Secondary source of income & 2 \\
Crisis & 13 \\
Employer in crisis & 6 \\
Passing through the economic crisis & 6 \\
Dissatisfaction with previous job & 1 \\
Level of satisfaction with the earnings & 24 \\
Satisfied with the income generated with Uber & 12 \\
Became the main source of income & 1 \\
Dissatisfaction with income generated with Uber & 11
\end{tabular}

Source: Research data

Uber driver in a developing country 
REGE

26,2

Petrie (2016) proposed that the self-employment is an essential process of Uber's and Airbnb's SE, which corresponds to the above mentioned interviewees along with others approached in our research (Respondents 3, 9 and 13). These ideas strengthen the substitution of the term "sharing" with a different one, also proposed by Petrie (2016), based on the idea that sharing does not mean sharing at all, i.e., when the resources provided by an individual can be leveraged through an internet-based platform (Petrie, 2016). Other authors substituted the term "self-employment" with "job on-demand" (Malin \& Chandler, 2016). They pointed out that the term "job on-demand" is a result of a difficulty to measure results in the post-industrial era and the practical change is in higher risks of unemployment.

The interviewees reported that driving is not their profession, demonstrating -according to our secondary data - that many drivers are new in this business and had different income opportunities before Uber (Kalanick, 2014). This can also be seen in Table I (interviewees' demographic variables) that 14 interviewees are new in the business, and the other 6 were private company drivers or taxi drivers. The data presented herein is neither in accordance with Kalanick's information nor the literature (Hall \& Krueger, 2016), which affirms that drivers could have had different income opportunities or were not led to apply to work for the company out of desperation, but due to the appealing flexibility nature of the work. The analysis herein shows that these interviewees would prefer to be somewhere else, but had to work with Uber out of desperation.

Specifically regarding to unemployment and its relationship with Uber, some authors identify this as a characteristic of Information Technology companies, which intensifies opportunities for businesses and people through social penetration (solution for demanded social improvements such as mobility, traffic efficiency, digital innovation and employment opportunities) (Watanabe, Naveed, \& Neittaanmäki, 2016; Watanabe, Naveed, Neittaanmäki, \& Fox, 2017). Cheng (2016) pointed out that other studies also indicate that the SE does imply in ways to help solve unemployment issues, but this could only be done through a stronger involvement of the government. This author also affirms that the government should be involved in such matters in order to avoid pernicious work relations, by understanding that these workers are the ones impacted by the work mode of the SE.

Despite the increase of unsatisfactory factors related to Uber, according to the respondents, there are moments in which working as a driver can be enjoyable, especially for those who appreciate the interaction with the passengers and other drivers (Respondents 2, 7, 9, 13 and 17). This reinforces that the shift to the post-industrial era, in which a whole generation sees working as something that can look less like work (Malin \& Chandler, 2016), indicates a change related to the merge between production and consumption experiences (Fontenelle, 2004, 2015). These changes gradually require that workers assume more flexible forms of work in order to supplement or substitute other regular forms of jobs. In the USA, at least 22 percent of adult workers already needed to take on-demand jobs (Malin \& Chandler, 2016), which is in accordance with the primary data collected herein that indicate that on-demand jobs are something anyone could need to do some day. Passengers interested in driving with Uber, as reported by the interviewees, are more common than those who are not. They ask questions about how much money they make, if it is their only job, how to sign in, how it works, etc.

Other informants saw in Uber the opportunity to complement their income. They allow themselves to really enjoy the benefits of the type of work by logging in and off at any time they want to. For them, Uber's greatest benefit is the flexibility: they drive for as long as they feel like driving and if they want to make more money, they can work some extra hours:

I got prepared to be dismissed from the company I work for, curiously they did manage to overcome the situation. Although this was just a trial, I liked it so much, I liked the people I meet and talk to, driving through the city, seeing new places. Besides, I get to make some extra money. (Respondent 17) 
As already analyzed before, this goes beyond the concept of SE; these are deeper changes in the structure of markets and how work and consumption are seen in society. The experiences from Uber exemplify how practical these changes are. For these interviewees, the characteristics of the work can be resumed, as well as indicated by Malin and Chandler (2016), as pleasant, flexible, like a play that does not seem like work, leave the house, get to talk to people, drive around the city and, in the end, make some money. Besides, "because gig workers do not need to invest in establishing a company and marketing to a consumer base, operating costs may be lower and allow workers' participation to be more transitory in the gig market" (Donovan, Bradley, \& Shimabukuru, 2016).

In our research it was not possible to explore the full benefits of the gig economy. This temporary goal related to becoming an Uber driver indicates certain criticisms or negative characteristics of the job, such as, "not liking the type of work," "insecurity," "loneliness" and the need to drive so many hours emphasizes some environmental externalities, like the precarious infrastructure, traffic jams, driving during rush hours and violence:

My goal is to leave Uber as soon as I get a job, this is just not for me, the traffic jam or sitting here driving all day, I do not like it. (Respondent 3)

We work too much, we make too little money, there is little transparency from the company, and if I really had another choice I would not be here. (Respondent 15)

Verboven and Vanherck (2016) affirmed that these negative reviews are common in other SE companies, defining dissatisfying as: lack of transparency, informality, bad work conditions, absence of compensation plans and others. Even though there seems to be a general dissatisfaction with the activity, the temporariness of the gig can be extended if different opportunities cannot make up to the money they are currently making, a fact that was pertinent in our analysis regarding lower income respondents:

I am making more money here than I was in my old job, this is very possible for anyone working with Uber. (Respondent 6)

Amid those who agree, driven by the possibility to make more money than in their previous occupations, foreseeing that with Uber they could change their income level, leaving behind their old professions, some interviewees took big steps toward this opportunity:

I had friends who were working with Uber and they encouraged me to give it a try. After I began working with Uber I realized I could make more money than in my old job. I asked my aunt (former employer) to dismiss me and now I only work with Uber, full time. (Respondent 8)

Kalanick (2014) made a presentation on the statistics of Uber's growth in London and he referred to some of the company's statistics on the drivers. Most of the 42,000 registered drivers are making more money and chose Uber instead of other job opportunities. A great part is new in the business, therefore Uber is expanding the number of jobs in the city in a very short period of time. When people are in a situation that they need to find any source of income due to extreme necessity, crisis and unemployment, Uber can be an opportunity that saves lives (Malin \& Chandler, 2016).

4.3.2 Level of satisfaction with the earnings from Uber. When analyzing the data collected that lead to group codes to describe the level of satisfaction with the earnings from driving with Uber, amid those who were satisfied - who were also the ones willing to complement their income - the dynamic pricing system is very relevant in their revenue, which helps deciding when and where to $\log$ in. For some, the earnings from Uber were similar to what they had in their previous activities, and the work flexibility was a positive aspect.
Uber driver in a developing country 
REGE

26,2

For these individuals, the income suffices their needs; on good days and during rush hours they compensate and raise their average earnings:

It can be rewarding even when driving just for a few days or during rush hours, I can make a reasonable amount of money and every now and then I can get dynamic pricing. It's a satisfying additional money to my income. (Respondent 17)

According to Kalanick (2014), on the secondary data, the pricing is based on reduced fares. The ideal pricing occurs when the number of rides increase - and the fares are reduced. According to the author, because drivers are getting more rides, they are making more money, even though prices go down. During the triangulation process carried out herein and the interviews conducted by us, it was possible to observe that the Uber's lowest fares result in drivers having to work extra hours in order to generate the same profit they would have had in shorter shifts (Nistal \& Regidor, 2016). This fact is another negative externality produced by the Uber's pricing system: drivers have to make ends meet, there are high maintenance costs, increased fuel prices, increase of mileage, vehicle's wear and tear, and drivers have to work more hours in an exhausting job during traffic jams (Respondents $3,7,15,20$ and 11 ).

Furthermore, the satisfied driver above mentioned (Respondent 17) fits the exact profile sought by the company: people who wish to make more money, driving their own car at any time and on the day they want to. Malin and Chandler (2016) also pointed out that the most satisfied people with the earnings and work were those looking after some extra money.

According to Watanabe et al. (2016) and Watanabe et al. (2017), unemployment and flexibility are the main success factors of Uber's expansion capacity: the drivers are independent (not employees), and, in a worldwide economic depression, more workers are willing to take on the risks and costs of self-employment. Malin and Chandler (2016) added that higher risks are assumed because of the higher flexibility; the risks are worth taking. Again, new regulations may create barriers and even affect the flexibility, which may also interfere in how people make their earnings in times of crisis and unemployment.

Amid the drivers who were discontent with their earnings, the arguments are more complex and detailed then the ones before described. Some interviewees calculated that, after deducting costs and Uber's 25 percent share, they are left with about 35 percent of the gross revenue. Respondents 11, 12 and 15 estimate that the costs with fuel are around 35 percent of the gross revenue; around 5 percent are destined to maintenance and car wash. Working $44 \mathrm{~h}$ per week (according to one of the interviewees), the net income of the driver would be around US\$650.00, which is below the average wage of the city, US\$910.00; according to Uber, the estimated earnings for $12 \mathrm{~h}$ shifts, six days a week, would be US $\$ 1,800.00$. The main complaint of this interviewee about the pricing system is that it does not take into account the depreciation while hiding the calculation of the actual income, especially taking into consideration individuals who bought cars and are paying off their debts.

According to Respondent 19 and other interviewees, in order to overcome problems such as the one previously described, they look for ways to build up their own client portfolio without Uber's mediation. Most importantly, with their own client portfolio, they would not transfer 25 percent of the profit of each ride to Uber. Such practice is allowed according to Uber contracts, especially considering that Uber encourages the autonomous status of the driver.

\section{Conclusions}

This research had an initial objective, which was later on divided in two. First, we wanted to understand the reasons why people decide to become Uber drivers. These reasons are more 
related to the possibility of transforming their private goods and own labor into productive assets than to other motives found in the literature of SE and car sharing. Differently from other studies with Uber drivers (Malin \& Chandler, 2016; Hall \& Krueger, 2016), the process of becoming a provider in this organization revealed to be much more a way to solve unemployment issues and to generate more income, instead of an adjustment to the market or a search for more flexible and complementary type of work.

In fact, regarding to the second part of the research's objective, "how it is to work with Uber," we conclude that such job can be a flexible and positive extra source of income. Social interaction with other drivers and passengers is also a positive aspect of the job. However, these items were evaluated as positive by the interviewees who are looking for flexibility and an extra income source. Nonetheless, these were the individuals with the right profile; i.e., the drivers that Uber focuses on attracting. Otherwise, if people are not willing to achieve these specific goals or have never had other independent contractor experience before (Lemmon et al., 2016), they are more likely to find the work conditions overall negative.

The general idea that Uber could be helping to generate jobs covers some externalities and leads people to decide applying for it. Externalities can be related to the existence of risks, informal work relation, pricing system disregarded of the actual operational costs, fluctuating fuel price, among others. This has also been found in the literature and points out that the world's regulations are not appropriate for the SE; even when applying the independent contractor framework to Uber drivers, the lack of negotiation rules the regulation out (Dyal-Chand, 2015; Redfearn, 2016).

The idea that Uber is a temporary movement in people's career was also found in the literature; however, we deepened this analysis herein. The literature reviewed in this paper proposes that temporariness of the job means a solution for people that in between jobs. In Brazil, however, in between jobs brings a different meaning, a severe and structural unemployment scenario. It was found that the availability of jobless car owners, who found themselves in great need for an immediate income opportunity, provides Uber with a high number of service providers, which also favors the reduced fare policy perpetuation.

These social challenges that involve the reality of the people behind Uber's wheels are in part solved by the opportunity to generate some income while the crisis is not over. The reality is that the daily operational costs overcome the net revenue expected, generating criticism and diminishing potential benefits. The fact that the type of work enables greater flexibility, occasional or as needed shifts for extra money seems to simplify the risks that eventually emerge.

Future studies can be carried out in other developing country cities and quantitative methodology researches may be developed in order to address these findings in a hierarchy of explanation factors and different correlations among the variables. Additionally, many other questions arose from the findings, showing that there are opportunities in the academia and in businesses to learn more about their market and the disruption impacts of the SE in several managerial fields, such as people management, marketing, business models, practices and technologies. What could be causing the drivers to be unsatisfied with Uber? What is the drivers' turnover and does the satisfaction level vary along time? Do the SE providers seek and are they used to working in a traditional model? How can Uber improve this scenario? Is it possible that the municipal governments have a relationship with the context of this study? What may be motivating Uber passengers to have interest in becming Uber drivers? How does the findings in this research relate to the providers of the SE to other forms of self-employment and even entrepreneurship?

\section{Note}

1. Translation of "Termos e Condições Gerais de Serviços de Intermediação Digital" - the Portuguese name of one of the contracts digitally signed by drivers in the admission process.
Uber driver in a developing country 
REGE

26,2

\section{References}

Abramovay, R. (2012). Muito além da economia verde. São Paulo: Editora Abrill.

Arnould, E. J., \& Rose, A. S. (2016). Mutuality: critique and substitute for Belk's sharing. Marketing Theory, 16(1), 75-99.

Bardhi, F., \& Eckhardt, G. M. (2012). Access-based consumption: the case of car sharing. Journal of Consumer Research, 39(4), 881-898.

Baumeister, C., \& Wangenheim, F. V. (2014). Access vs. ownership: understanding consumers' consumption mode preference. SSRN Electronic Journal. doi: 10.2139/ssrn.2463076.

Belk, R. (2007). Why not share rather than own?. The Annals of the American Academy of Political and Social Science, 611(1), 126-140.

Belk, R. (2010). Sharing. Journal of Consumer Research, 36(5), 715-734.

Belk, R. (2014). Sharing versus pseudo-sharing in web 2.0. The Anthropologist, 18(1), 7-23.

Belk, R. (2016). Accept no substitutes: a reply to Arnould and Rose. Marketing Theory, 16(1), $143-149$.

Benkler, Y. (2004). Sharing nicely: on shareable goods and the emergence of sharing as a modality of economic production. The Yale Law Journal, 114(2), 273-358. doi: 10.2307/4135731.

Bird-David, N. (1990). The giving environment: another perspective on the economic system of gatherer-hunters. Current Anthropology, 31(2), 189-196.

Botsman, R., \& Rogers, R. (2011). What's mine is yours: how collaborative consumption is changing the way we live, London: Collins.

Burtch, G., Carnahan, S., \& Greenwood, B. N. (2018). Can you gig it? An empirical examination of the gig economy and entrepreneurial activity. Management Science, 64, 44p. doi: 10.1287/mnsc.2017.2916.

Cannon, B., \& Chung, H. (2014). Framework for designing co-regulation models well- adapted to technology-facilitated sharing economies. Santa Clara Computer \& High Technology Law Journal, 31(1), 23-96.

Cannon, S., \& Summers, L. H. (2014). How Uber and the sharing economy can win over regulators. Harvard Business Review, 13(10), 24-28.

Carr, C. T., Hall, R. D., Mason, A. J., \& Varney, E. J. (2017). Cueing employability in the gig economy: effects of task-relevant and task-irrelevant information on Fiverr. Management Communication Quarterly, 31(3), 409-428.

Cheng, M. (2016, August). Sharing economy: a review and agenda for future research. International Journal of Hospitality Management, 57, 60-70.

Cohen, B., \& Kietzmann, J. (2014). Ride on! Mobility business models for the sharing economy. Organization \& Environment, 27(3), 279-296.

Donovan, S. A., Bradley, D. H., \& Shimabukuru, J. O. (2016). What Does the Gig Economy Mean for Workers? Washington, DC: Congressional Research Service. Available from: https:/fas.org/sgp/ crs/misc/R44365.pdf (accessed October 30, 2017).

Dyal-Chand, R. (2015). Regulating sharing: the sharing economy as an alternative capitalist system. Tulane Law Review, 90(2), 241-309.

Eckhardt, G. M., \& Bardhi, F. (2015, January). The sharing economy isn't about sharing at all. Harvard Business Review, 28. Available from: https://hbr.org/2015/01/the-sharing-economy-isnt-aboutsharing-at-all (accessed July 15, 2018).

Fontenelle, I. A. (2004). Mídia, acesso e mercado da experiência. Revista Contracampo, Nos 10-11, 185-200.

Fontenelle, I. A. (2015, September). Organisations as producers of consumers. Organization, 22(5), 644-660. doi: 10.1177/1350508415585029.

Foresight Alliance (2016). The future of work. Available from: www.foresightalliance.com (accessed July 19, 2018).

Gansky, L. (2012). The Mesh: why the Future of Business is Sharing. London: Penguin.

Gil, A. C. (2002). Como elaborar projetos de pesquisa, São Paulo: Editora Atlas. 
Graham, M., Hjorth, I., \& Lehdonvirta, V. (2017). Digital labour and development: impacts of global digital labour platforms and the gig economy on worker livelihoods. Transfer: European Review of Labour and Research, 23(2), 135-162. Available from: https://oi.org/10.1177/ 1024258916687250

Uber driver in a developing country

Granovetter, M. (1985). Economic action and social structure: the problem of embeddedness. American Journal of Sociology, 91(3), 481-510.

Granovetter, M. (2005). The impact of social structure on economic outcomes. The Journal of Economic Perspectives, 19(1), 33-50.

Hall, J. V., \& Krueger, A. B. (2016). An analysis of the labor market for Uber's driver-partners in the United States. (No. w22843), Cambridge, MA: National Bureau of Economic Research.

Huwer, U. (2004). Public transport and csar-sharing - benefits and effects of combined services. Transport Policy, 11(1), 77-87.

Kalanick, T. (2014). Uber, speaking at the IoD Annual Convention 2014. Available from: www.youtube. com/watch?v=Vi_AilQolJ8 (accessed July 12, 2016).

Lamberton, C. P., \& Rose, R. L. (2012). When is ours better than mine? A framework for understanding and altering participation in commercial sharing systems. Journal of Marketing, 76(4), 109-125.

Leighton, P. (2016). Professional self-employment, new power and the sharing economy: some cautionary tales from Uber. Journal of Management \& Organization, 22(6), 859-874.

Lemmon, G., Wilson, M. S., Posig, M., \& Glibkowski, B. C. (2016). Psychological contract development, distributive justice, and performance of independent contractors: the role of negotiation behaviors and the fulfillment of resources. Journal of Leadership \& Organizational Studies, 23(4), 424-439.

Lessig, L. (2008). Remix: Making art and Commerce Thrive in the Hybrid Economy, London: Penguin.

Malin, B. J., \& Chandler, C. (2016). Free to work anxiously: splintering precarity among drivers for Uber and Lyft. Communication. Culture \& Critique, 10(2), 382-400.

Martin, C. J., Upham, P., \& Budd, L. (2015). Commercial orientation in grassroots social innovation: insights from the sharing economy. Ecological Economics, 118, 240-251.

Moraes, R. (1999). Análise de conteúdo. Revista Educação, 22(37), 7-32.

Nistal, P. D., \& Regidor, J. R. F. (2016, August 8). Comparative study of Uber and regular taxi service characteristics. Proceedings of the 23rd Annual Conference of the Transportation Science Society of the Philippines, Quezon City, Philippines. Available from: http://ncts.upd.edu.ph/tssp/ wp-content/upload/2016/08/Paronda-et-al.pdf (accessed August 13, 2017).

Petrie, C. (2016). Emergent collectives Redux: the sharing economy. IEEE Internet Computing, 20(4), $84-86$.

Polanyi, K. (1944/2013). A grande transformação. São Paulo: Leya.

Rayle, L., Dai, D., Chan, N., Cervero, R., \& Shaheen, S. (2016). Just a better taxi? A survey-based comparison of taxis, transit, and ridesourcing services in San Francisco. Transport Policy, 45, 168-178. doi: 10.1016/ j.tranpol.2015.10.004.

Rayle, L., Shaheen, S., Chan, N., Dai, D., \& Cervero, R. (2014). App-based, on-demand ride services: comparing taxi and ridesourcing trips and user characteristics in San Francisco. University of California Transportation Center (UCTC), Berkeley, CA: University of California.

Redfearn, R. L. (2016). Sharing economy misclassification: employees and independent contractors in transportation network companies. Berkeley Technology Law Journal, 31(2), 1022-1056.

Rifkin, J. (2001). A era do acesso, São Paulo: Makron Books.

Schor, J. B., \& Attwood-Charles, W. (2017). The sharing economy: labour, inequality and sociability on for-profit platforms. Sociology Compass, 11(8), 1-16.

Schor, J. B., Fitzmaurice, C., Carfagna, L. B., Attwood-Charles, W., \& Poteat, E. D. (2016, February). Paradoxes of openness and distinction in the sharing economy. Poetics, 54, 66-81.

Shaheen, S. A., Chan, N. D., \& Gaynor, T. (2016). Casual carpooling in the San Francisco bay area: understanding user characteristics, behaviors, and motivations. Transport Policy, 51, 1-9. doi: 10.1016/j.tranpol.2016.01.003. 
REGE

26,2

Silveira, L. M., Petrini, M., \& dos Santos, A. C. M. Z. (2016). Economia compartilhada econsumo colaborativo: o que estamos pesquisando? Revista de Gestão, 23(4), 298-305.

Steininger, K. W. (1994). Illusion in the depletion of common property resources. International Journal of Environment and Pollution, 4(3), 267-282.

Valente, E. (2017). A economia da partilha entre o compartilhamento, o mercado e a sustentabilidade: Um estudo de caso do processo produtivo do Uber. Dissertação de mestrado, Pontifícia Universidade Católica de Minas Gerais, Belo Horizonte, MG, Brasil.

Valente, E., \& Patrus, R. (2019). Sobre a economia da partilha e o mercado da partilha: uma análise do Uber como pseudocompartilhamento. Revista Gestão \& Tecnologia, 19(1), 225-244. doi: https://doi.org/10.20397/2177-6652/2019.v19i1.1315.

Verboven, H., \& Vanherck, L. (2016, August). The sustainability paradox of the sharing economy. uwf UmweltWirtschaftsForum, 24(4), 303-314. Available from: https://doi.org/10.1007/ s00550-016-0410-y

Watanabe, C., Naveed, K., \& Neittaanmäki, P. (2016). Co-evolution of three mega-trends nurtures un-captured GDP - Uber's ride-sharing revolution. Technology in Society, 46, 164-185. Available from: https://doi.org/10.1016/j.techsoc.2016.06.004

Watanabe, C., Naveed, K., Neittaanmäki, P., \& Fox, B. (2017). Consolidated challenge to social demand for resilient platforms-lessons from Uber's global expansion. Technology in Society, 48, 33-53. doi: 10.1016/j.techsoc.2016.10.006.

Yin, R. (2010). Estudo de caso: planejamento e métodos. Porto Alegre: Bookman.

\section{Further reading}

Belk, R. (2013). You are what you can access: sharing and collaborative consumption online. Journal of Business Research, 67(8), 1595-1600.

Castelle, M. (2016). Marketplace platforms or exchanges? Financial metaphors for regulating the collaborative economy. Economic Sociology_the European Electronic Newsletter, 17(3), 14-26.

De Stefano, V. (2015, October 28). The rise of the "just-in-time workforce": on-demand work, crowdwork, and labor protection in the "gig-economy". Comparative Labor Law \& Policy Journal, forthcoming. Available from: https://ssrn.com/abstract=2682602; http://dx.doi.org/10.2 139/ssrn.2682602

Fang, B., Ye, Q., \& Law, R. (2016). Effect of sharing economy on tourism industry employment. Annals of Tourism Research, 57(C), 264-267.

IBGE (2016). Acesso à Internet e à Televisão e Posse de Telefone Móvel Celular para Uso Pessoal 2013 - PNAD. Instituto Brasileiro de Geografia e Estatística, Recuperado de http://ibge.gov.br/home/ estatistica/populacao/acessoainternet2013/default_xls_2013.shtm

Nurvala, J. P. (2015). 'Uberisation' is the future of the digitalised labour market. European View, 14(2), 231-239.

Richardson, L. (2015). Performing the sharing economy. Geoforum, 67, 121-129. Available from: https://doi.org/10.1016/j.geoforum.2015.11.004

Steininger, K., Vogl, C., \& Zettl, R. (1996). Car-sharing organizations: the size of the market segment and revealed change in mobility behavior. Transport Policy, 3(4), 177-185.

\section{Corresponding author}

Roberto Patrus can be contacted at: robertopatrus@pucminas.br

Associate Editor: Felipe Lara

For instructions on how to order reprints of this article, please visit our website:

www.emeraldgrouppublishing.com/licensing/reprints.htm

Or contact us for further details: permissions@emeraldinsight.com 